\title{
ISOLATION OF AN OIL PALM CONSTITUTIVE PROMOTER DERIVED FROM UBIQUITIN EXTENSION PROTEIN (uер2) GENE
}

\section{SUBHI SITI MASURA*; GHULAM KADIR AHMAD PARVEEZ* and OMAR ABD RASID*}

\begin{abstract}
Constitutive promoters are essential component in genetic engineering. The promoters are usually derived from genes that are constitutively expressed or function as housekeeping genes. In this study, the ubiquitin extension protein (uep2) gene was identified as a constitutively expressed gene in oil palm. The 5 ' region of the oil palm uep2 gene was isolated and the promoter truncation analysis was performed. The full length of uep2 (uep2a) and its truncation derivatives (uep2b and uep2c) were linked to $\beta$-glucuronidase (gus) reporter gene. The strength and the activity of the uep2 promoter were transiently evaluated in various oil palm tissues and tobacco leaves. Histochemical GUS analysis showed that the activity of truncated uep2b promoter was higher than the full length promoter and uep2c derivative in most tissues tested. Result also showed that uep2b was capable of directing the expression of GUS in all tissues with the high activity detected in oil palm embryoid, green leaves, and tobacco leaves. The full length of uep2 (uep2a) promoter also exhibited the ability to direct the expression of GUS in all tissues with the high activity detected in the plantlet stem. By contrast, although the uep2c showed high activity in young leaves and embryoid, a significant decrease of GUS expression was seen in green tissues. These results indicated that the region between position -1096 and -3237 is essential for constitutive transcriptional regulation as deletion of the region resulted in a significant decrease in the promoter activity. Though maize ubi1 and CaMV35S promoters showed a relatively higher activity than uep2, the uep2 has the ability to induce the constitutive GUS expression in all tissues tested. These results showed that 5' flanking region of uep2 gene is active in oil palm and tobacco, suggesting that the promoter could be used as an alternative promoter for driving constitutive expression of transgenes in oil palm and other plants.
\end{abstract}

\section{Keywords: oil palm, constitutive promoter, transient expression.}

Date received: 20 March 2018; Sent for revision: 27 March 2018; Received in final form: 23 July 2018; Accepted: 18 December 2018.

\section{INTRODUCTION}

Oil palm has been known as a high-yielding source of vegetable oils and is widely used in food and oleochemical industries. Being a Malaysian major commodity crop, the oil palm industry has to remain competitive and sustainable to face major

\footnotetext{
Malaysian Palm Oil Board,

6 Persiaran Institusi, Bandar Baru Bangi,

43000 Kajang, Selangor, Malaysia.

E-mail:masura@mpob.gov.my
}

challenges such as unstable commodity price, limited acreage for plantation and labour shortage (Parveez et al., 2015). Biotechnology offers vast opportunities for energising and revolutionising the oil palm industry, and one of the initiatives is through genetic engineering (Ravigadevi et al., 2009). The technology provides novel opportunities to improve oil palm planting materials with the production of high value-added products. The main target of oil palm genetic engineering is to develop high oleate palm as feedstock for oleochemicals 
industry. Other targets are to produce oil palm with high content of stearic acid, palmitoleic acid, ricinoleic acid, lycopene and biodegradable plastics (Rasid et al., 2009; Parveez et al., 2015; Hanin et al., 2016; Masura et al., 2017; Zubaidah et al., 2018; Masani et al., 2018). The success to genetically engineer plants, including oil palm, relies on many factors, and one of them is the use of efficient promoters to drive the expression of transgenes (Potenza et al., 2004). The promoter sequence will determine when and where within the organism the transgene is expressed. Constitutive promoters will be a choice if continuous and ubiquitous expression of transgenes is desired throughout the plant cells (Douglas Des Moines, 2004).

Constitutive promoters are normally used to establish a reliable transformation system in plant genetic engineering by expressing reporter and selectable marker genes. The promoter is also useful to accumulate high levels of desired proteins for isolation and to produce compounds that require continuous activities all over the organism or developmental stages (Li et al., 2014). Constitutive promoters usually used in genetic transformation were from plant and pathogen origins. Plant derived constitutive promoters usually used in transgenic research are such as Act1 (McElroy et al., 1990), maize ubi1 (Christensen et al., 1992; Cornejo et al., 1993), pEmu (Last et al., 1991), RUBQ1 and RUBQ2 (Wang and Oard, 2003). These promoters are active for expressing gene of interest in monocots but their efficiencies are sometimes distinct in various ways. Besides, pathogen-origin derived promoters such as CaMV35S (Odell et al., 1985; Fang et al., 1989; Benfey and Chua, 1990) is numerously utilised in genetic engineering. High expression of transgene is usually produced by using this viral derived promoter in both monocots and dicots (Potenza et al., 2004). However, despite their advantages, the use of viral-derived promoters have several limitations. First concern is the perception of risk to human health disfavours its uses, especially for commercial purposes (Ho et al., 1999; Potenza et al., 2004). Another possible limitation is due to the cell ability to recognise these sequences as foreign and inactivate them (Elmayan and Vaucheret, 1996; Potenza et al., 2004), which then would lead to gene silencing. The stable shutdown of gene activity throughout the plant could occur due to gene silencing (Kloti et al., 2002), which could also affect the promoter efficiency. Gene silencing is unpredictable, but it may be less common when plant transformation is performed by using constitutive promoters derived from plant origin (Potenza et al., 2004).

Oil palm native endogenous constitutive promoters derived from translationally control tumour protein (TCTP) (Masura et al., 2011) and ubiquitin extension protein (uep1) genes (Masura et al., 2010) have been isolated and characterised.
These promoters are active constitutively and could be used for driving the expression of transgenes in oil palm or other plants. TCTP and uep genes belong to a multiple gene family. We have decided to work further on the uep gene by isolating and characterising another member of the gene family, namely uep2. UEP consists of a single ubiquitin monomer (76 amino acids) translationally fused to ribosomal protein. UEP exists in two forms in higher plants (Callis et al., 1990) as well as in other eukaryotic organisms (Monia et al., 1990; Ozkaynak et al., 1987). The single ubiquitin monomer is translationally fused to a coding region of either 76 to 81 amino acid or a 52 amino acid ribosomeassociated polypeptide. As uep1, иep2 is also the ubiquitin extension protein that contains 80 amino acid residues. The gene is involved in ribosome biogenesis, the most important component in cellular process of translation (Finley et al., 1989; Monia et al., 1990). Promoters derived from uep gene have been isolated from yeast (Ozkaynak et al.,1987) and several plants including tomato (Hoffman et al., 1991), barley (Gausing and Jensen, 1986), potato (Garbarino and Belknap, 1994), Arabidopsis (Callis et al., 1990) and Jatropha curcas (Toa et al., 2015).

The availability of oil palm uep 2 promoter will increase the range of promoters for the genetic engineering work. More endogenous monocot constitutive promoters are required for multiple transgene stacking and cisgenesis technologies (Chen et al., 2010; Holme et al., 2013). Utilisation of the different promoters for the different transgenes will possibly reduce the risk of homolog-dependent gene silencing in plant transformation system (Xiao et al., 2005). Thus, isolation and the use of more efficient promoters for efficient genetic transformation are essential as the success of genetic engineering technology also depends on their efficacious selection and use (Potenza et al., 2004).

\section{MATERIALS AND METHODS}

\section{Plants Materials}

The oil palm (Elaeis guineensis var Tenera) plant was used for isolating the gene promoter. Oil palm genomic DNA was prepared from oil palm green leaves using the method by Doyle and Doyle (1990). Total RNA from various oil palm tissues was extracted using method of Zeng and Yang (2002) with modifications.

\section{Expression of Oil Palm Endogenous Gene}

The expression pattern of $u e p 2$ gene was analysed through Northern analysis. About $15 \mu \mathrm{g}$ of total RNA from different oil palm tissues were heated for 10 min at $65^{\circ} \mathrm{C}$ in RNA loading buffer. The denatured 
total RNA was loaded into the formaldehydecontaining agarose gel and electrophoresed in $1 \mathrm{X}$ MOPS buffer at 5 to $7.5 \mathrm{~V} \mathrm{~cm}^{-1}$. Then the gel was stained in ethidium bromide (EtBr) solution (0.5 $\mu \mathrm{g} \mathrm{ml}^{-1}$ ) for $2 \mathrm{~min}$ and followed by destaining in sterile $\mathrm{dH}_{2} \mathrm{O}$ for $90 \mathrm{~min}$. By using the capillary transfer method, the total RNA was transferred onto a nylon membrane (Hybond $\mathrm{N}+$ Amersham) for overnight. The membrane was fixed by UV cross-linking using XL-1500 UV Crosslinker (Spectronics Co.) set at $1.2 \mathrm{~J} \mathrm{~cm}^{-2}$, for $40 \mathrm{~s}$. The cDNA fragment was purified and labelled with $\left[\alpha^{32} \mathrm{P}\right]$ dCTP radioisotope using Megaprime ${ }^{\mathrm{TM}}$ DNA Labelling System (Amersham Life Science). Pre-hybridisation, hybridisation and membrane washing were carried out following the standard technique of Sambrook et al. (1989). The membranes were exposed to Kodak XAR-5 film with an intensifying screen at $-80^{\circ} \mathrm{C}$ for a week.

\section{Promoter Isolation, Cloning and Sequence Analysis}

A genomic sequence of uep2 gene was obtained from oil palm genome database (http:/ / genomsawit.mpob.gov.my). The targeted DNA was amplified in a reaction containing $1 \mathrm{X}$ High Fidelity PCR buffer, $0.2 \mathrm{mM}$ of each dNTP, $200 \mathrm{nM}$ of gene specific primers and 1 unit Platinum ${ }^{\circledR}$ Taq DNA High Fidelity Polymerase (Invitrogen ${ }^{\mathrm{TM}}$ ). The amplification was carried out by denaturing the mixture at $94^{\circ} \mathrm{C}$ for $2 \mathrm{~min}$, then followed with denaturation at $94^{\circ} \mathrm{C}$ for $15 \mathrm{~s}$, annealing at $60^{\circ} \mathrm{C}$ for $30 \mathrm{~s}$ and extension at $68^{\circ} \mathrm{C}$ for $1 \mathrm{~min}$, for 35 cycles. The final extension was performed for $7 \mathrm{~min}$ at $72^{\circ} \mathrm{C}$. The polymerase chain reaction (PCR) products were fractionated by agarose gel electrophoresis, purified and ligated into pGEMT-Easy vector. The ligation mixture was then transformed into ECOS ${ }^{\mathrm{TM}}$ (Yeastern Biotech) competent cells. The Qiaprep Spin Miniprep Kit (QIAGEN) was used to isolate the plasmid DNA. The digestion of recombinant clones with appropriate restriction enzymes was performed to confirm the DNA insertion. The promoter in silico analysis was performed using VectorNTI software (Invitrogen) and available databases online such as Softberry, PlantPan (Chang et al., 2008) and PlantCare (Lescort et al., 2002) to identify the presence of important cis-regulatory elements.
PCR amplification was carried out to generate 5 -truncations of uep2 promoter from the full length construct. Two forward primers (uep2FA and uep2FB) and a reverse primer (uep2R) with additional restriction sites were used for the amplification (Table 1). The two truncated derivatives were ligated into pGEMT-Easy vector and transformed into ECOS ${ }^{\mathrm{TM}}$ (Yeastern Biotech) competent cells. Resulted colonies were screened for insert and the final confirmation was performed by DNA sequencing.

\section{Construction of Transformation Vector}

Constructions of transformation vectors for uep2 and its truncation fragments were carried out using pBI221 based vector by removing CaMV35S promoter region. The fragments were digested from the intermediate cloning vectors using suitable restriction enzymes. The digestion was carried out by adding $5 \mu \mathrm{g}$ DNA, $1 \mathrm{X}$ restriction buffer and 1 unit of each restriction enzyme in $50 \mu \mathrm{l}$ reaction mixtures and incubated at $37^{\circ} \mathrm{C}$ for overnight. The DNA fragments were purified using QIAquick Gel Extraction Kit (QIAGEN) after being fractionated in agarose gel electrophoresis. The DNA promoter fragment was ligated into the digested pBI221 vector in reaction mixture consist of $10 \mathrm{ng}$ of vector plasmid, $50 \mathrm{ng}$ of the purified DNA insert, 1X T4 ligation buffer and 1 unit of T4 ligase. The ligation mixture was transformed into ECOS ${ }^{\mathrm{TM}}$ (Yeastern Biotech) competent cells according to manufacturer procedure. The recombinant clones were screened using restriction analysis and sequenced.

\section{Plant Materials and Particle Bombardment}

The activity of uep2 promoter was evaluated in different oil palm tissues and green leaves of tobacco. The young leaflet from a mature palm, embryoid, green leaves, root and stem of oil palm plantlets and tobacco green leaves were cultured on EC medium [MS salts (Murashige and Skoog, 1962), $Y_{3}$ vitamins (Eeuwans, 1976), 1 mg litre ${ }^{-1}$ napthaleneacetic acid (NAA), $30 \mathrm{~g}$ litre $^{-1}$ sucrose and $0.8 \%$ agar]. The explants were cut into small pieces before placing onto the medium. The tissues were then pre-cultured in dark at $28^{\circ} \mathrm{C}$, one day prior to bombardment. The precipitation of plasmid DNA and the particle bombardment of oil palm tissues

TABLE 1. PRIMER SEQUENCES FOR $u e p 2$ PROMOTER ANALYSIS

\begin{tabular}{lcl}
\hline Primers & Restriction site & \multicolumn{1}{c}{ Sequences } \\
\hline uep2pFA & $S p h 1$ & $5^{\prime}$ GCA TGC CAG TTT GAG AAT CAG AA AAA3' \\
uep2pR & $X b a 1$ & $5^{\prime}$ TCT AGA CTT GGC AGC GGC AAC GGC GCT 3' \\
uep2pFB & $P s t 1$ & $5^{\prime}$ CTG CAG GAC CCA AGC CCA TTC AAA AAT TT 3' \\
uep2pFC & $P s t 1$ & $5^{\prime} \underline{\text { CTG CAG TGC AGG GGT TTC TTT CAA ATA ATC 3' }}$ \\
\hline
\end{tabular}

Note: uep2 - ubiquitin extension protein. 
was carried out using Bio-Rad PDS-1000 (Bio-Rad, Hercules, CA, USA) delivery system as described by Parveez et al. (2000). All tissues were bombarded by using 1100 psi rapture discs and at $6 \mathrm{~cm}$ distance between stopping plate to target tissues, except for green leaf, which was bombarded using 1350 psi rapture disc and at $4.5 \mathrm{~cm}$ distance between stopping plate to target tissues. The bombarded tissues were incubated at $28^{\circ} \mathrm{C}$ in the dark for two days before the GUS histochemical assay was performed.

\section{GUS Histochemical Assay}

The $\beta$-glucuronidase (GUS) histochemical assay was performed according to Klein et al. (1987) and Parveez et al. (2000). The bombarded tissues were stained in the histochemical reagent containing 0.1 $\mathrm{M} \mathrm{NaPO}_{4}$ buffer pH7.0, 0.5 mM K-ferrocyanide, 0.5 $\mathrm{mM}$ K-ferricyanide, $0.01 \mathrm{M}$ EDTA, $1 \mathrm{mg} \mathrm{ml}^{-1} \mathrm{X}$-gluc (5-Bromo-4-Chloro-3-Indolyl- $\beta$-D-glucuronide), 1 $\mu \mathrm{l} \mathrm{ml} \mathrm{l}^{-1}$ Triton- $\mathrm{X}$ and $20 \%$ methanol $(\mathrm{v} / \mathrm{v})$ at $37^{\circ} \mathrm{C}$ for overnight $(16 \mathrm{hr})$. The tissues were fixed in the FAA (5\% formaldehyde, $5 \%$ acetic acid and $37.5 \%$ ethanol) solution to stop the GUS reaction. The green tissues were soaked in $70 \%$ ethanol to clear the chlorophyll content. The Nikon UFX-DX microscope system was used to score the GUS blue spots optically.

\section{RESULTS AND DISCUSSION}

\section{Identification of uep 2 as an Oil Palm Constitutively Expressed Gene}

The present work describes the identification of an oil palm endogenous constitutively expressed gene and the isolation of its promoter for plant genetic transformation. Detailed analysis was carried out by comparing the uep1 (Accession number: XM_010923047) and uep2 (Accession number: XM_019854938) sequences. By using pairwise sequence alignment tool (Emboss Needle), results showed that the two genes shared $92.4 \%$ similarity of coding region, and $61.1 \%$ and $52.2 \%$ similarity of $5^{\prime}$ and $3^{\prime}$ non-coding regions, respectively.

Northern analysis was performed to validate the constitutive expression of uep2. Results indicated that uep 2 transcript was detected in total RNA of various oil palm tissues including mesocarp at $6,8,12,17$ weeks after anthesis (WAA), kernel, green leaves, flower, root, and embryoid (Figure 1). A high level of uep 2 expression was detected at the early stages of mesocarp development, namely at the 5 to 12 WAA before it was slightly decreased at later stages. The high level of transcript was also detected in the root and embryoid. Results indicated that the uep2 expression pattern was similar to the expression pattern of oil palm uep1 (Masura et al., 2010). The expression was high in young tissues and in the tissues containing meristematic cells. The expression profile of uep 2 coincides with its role in ribosome biogenesis. Ribosome is the most important component in the cellular process of translation. The high expression of uep 2 in these tissues is essential for an active protein synthesis. This pattern of expression were observed in tomato (Hoffman et al., 1991), Arabidopsis (Callis et al., 1990), barley (Gausing and Jensen, 1986) and potato (Garbarino and Belknap, 1994). Although the expression level varied among the tissues, uep 2 was ubiquitously expressed throughout the different development stages of oil palm.

\section{Isolation of Promoter Region and Sequence Analysis}

The detailed analysis of иер 2 sequence was carried out using the oil palm genome and transcriptome databases. The advances in oil palm genome sequencing and the availability of public access databases have accelerated the discovery of oil palm novel promoters and their important cisacting elements. The uep 2 gene was found to contain 471 nucleotide residues which code for 157 amino acids with the calculated molecular mass of 17.43 $\mathrm{kDa}$. It also contains $113 \mathrm{bp}$ of $5^{\prime}$ end and $312 \mathrm{bp}$ of $3^{\prime}$ end untranslated regions including its poly $\mathrm{A}^{+}$tail. Upstream of uep2 start codon, only a total of 3336 bp fragment that has the sequence information. The sequences of region beyond that are ambiguous. Since this nucleotide bases reads may contain regulatory elements of $u e p 2$, the region was isolated for promoter analysis. The location of putative TSS was predicted at nucleotide A (Adenine) which is $99 \mathrm{bp}$ upstream of the start codon. A potential TATA (TATAAAA) box sequence was identified at about $-30 \mathrm{bp}$ upstream of transcription start site (TSS). A CAAT-box sequence (CAAT) was present at $27 \mathrm{bp}$ upstream of the TATA-box sequence, at position -64. Usually, 50-100 bp sequences adjacent to the TSS is the location of core promoter region, while the upstream promoter regions of $1-2 \mathrm{~kb}$ or

a)

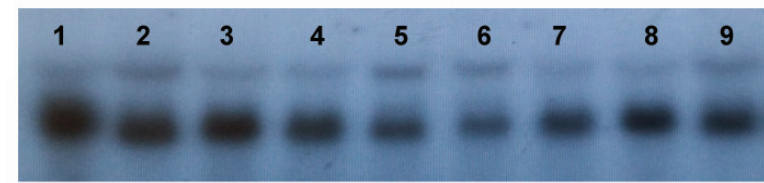

b)

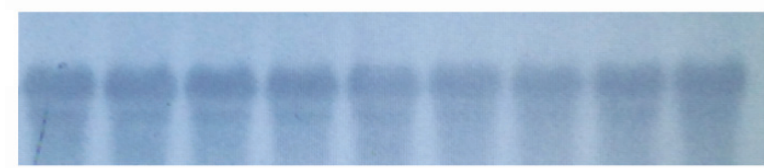

Figure 1. Northern analysis of ubiquitin extension protein (uep2) gene (a). Each lane contained $15 \mu \mathrm{g}$ of total RNA prepared from different tissues of oil palm. Lane 1-4: mesocarp 6, 8, 12, 17 weeks after anthesis (WAA), lane 5: kernel 12 WAA, lane 6: green leaves, lane 7: flower, lane 8: root, lane 9: embryoid. Equal loading of RNA was verified with $28 \mathrm{~S}$ ribosomal DNA (b). 
more contains several cis-regulatory elements or DNA motifs that serve as the binding sites for gene specific regulators (Wu et al., 2001). The analysis of the uеp 2 promoter sequence has revealed a number of conserved DNA motifs upstream of TSS. The putative cis-elements were found with different copy numbers and varying distribution pattern (Figure 2). These were the potential binding sites for transcription factors. The sequence of uep2 promoter and the predicted putative cis-regulatory elements were shown in Figure 2 and summarised in Table 2.

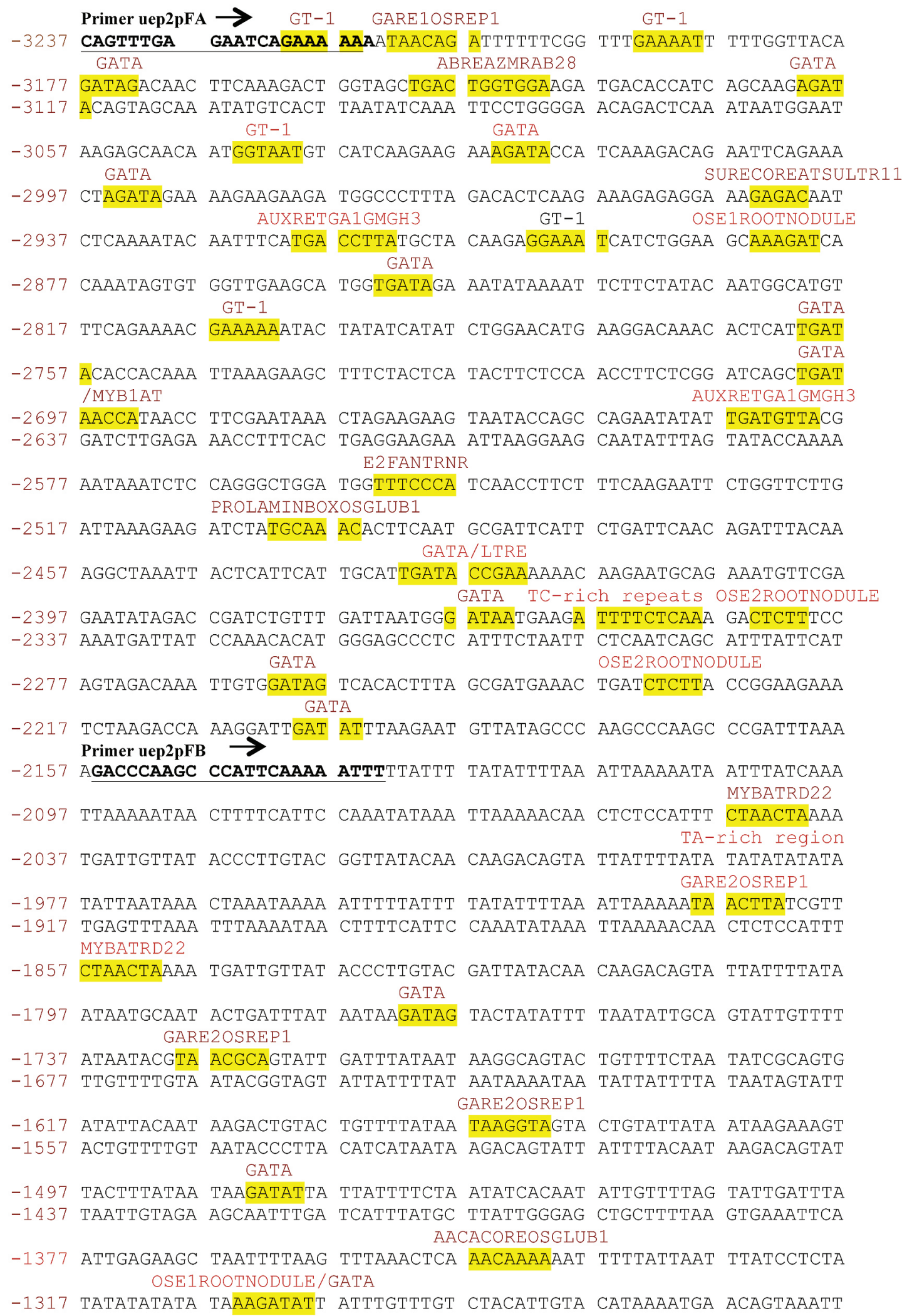




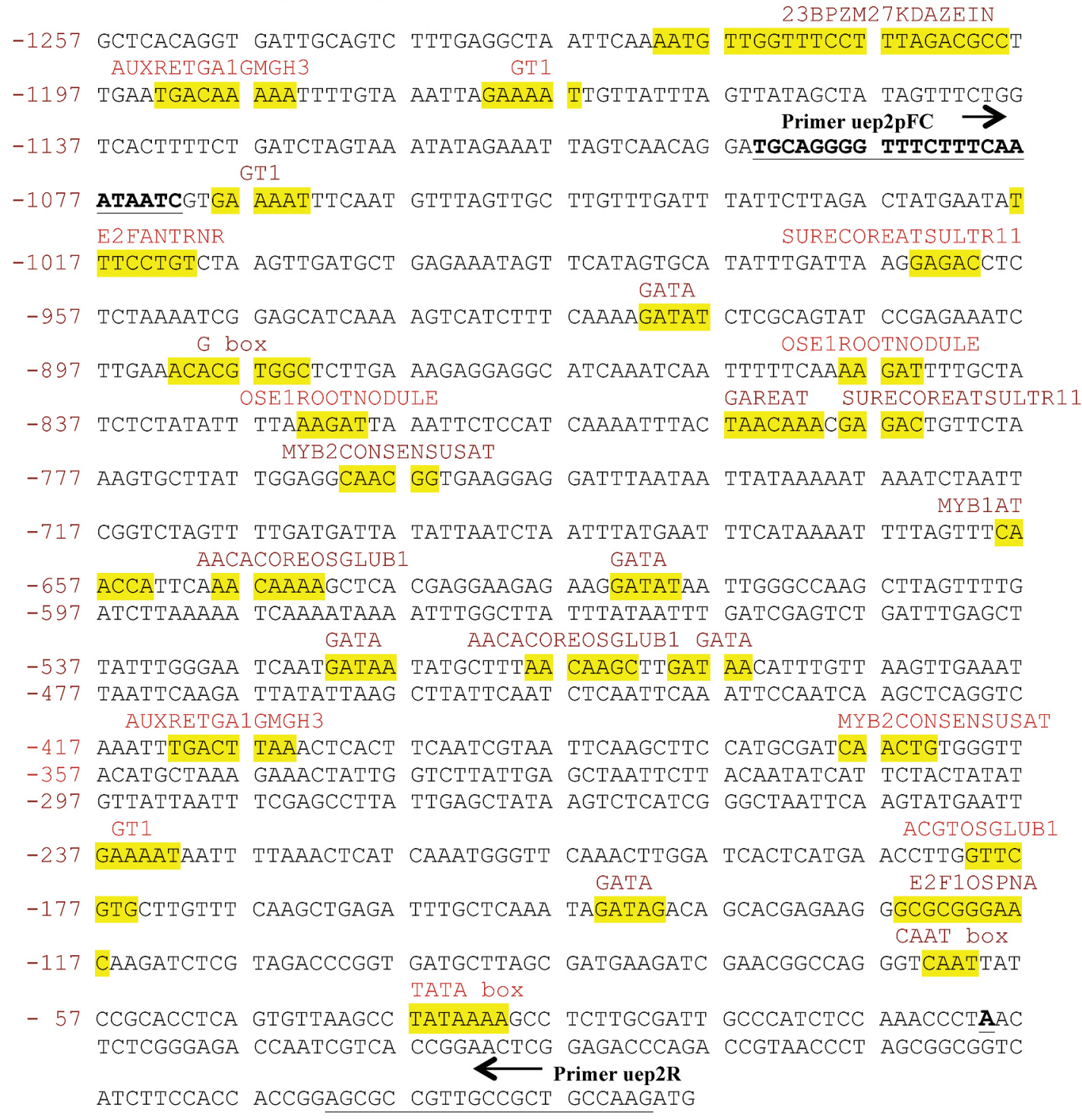

Figure 2. The nucleotide sequence of oil palm ubiquitin extension protein (uep2) promoter. The position of putative transcription start site (Adenin) is indicated with large and bold font and underlined is numbered as +1 . Putative regulatory elements on both strands are shadowed. Arrows indicated the location of uep2pFA, uep2pFB, uep2pFC and uep2pR primers.

In summary, the results showed that uep2 promoter contains multiple cis-acting elements which may contribute to its constitutive activity. The oil palm constitutive $u e p 1$ and TCTP (Masura et al., 2010; 2011), and other constitutive promoters from Jatropha curcas (JcUEP) (Toa et al., 2015), Brassica rapa (beta tubulin) (Mubeen et al., 2015) and tomato (sucrose synthase) (Bacha et al., 2015), were also shown to contain multiple putative cis-elements that are associated with light regulated, hormones responsiveness, abiotic and biotic stresses, and tissue specificity, which may contribute to the total activity of the promoters. The constitutive promoters such CaMV35S also contain a string of separate elements, each contributing to the high constitutive expression seen in plants (Fang et al., 1989). The individual elements that are classified as 'Domain $\mathrm{A}^{\prime}$ and 'Domain $\mathrm{B}^{\prime}$ in $35 S$ have been found to be involved in tissue-specific expression (Benfey et al., 1990). For uep2, the functions of these putative regulatory elements are yet to be determined. Results of some studies have suggested that constitutive promoters of higher plants may not behave as their viral counterparts (Odell et al., 1985; Benfey and Chua, 1990). They may not be a collection of numerous tissue specific (motifs) (Odell et al., 1985; Benfey and Chua, 1990), but may have non-specific elements that are well conserved and simply more efficient at protein recruitment of transcription (HernandezGarcia and Finer, 2014). For example, G box like 
TABLE 2. PUTATIVE CIS-ACTING ELEMENTS IN uep2 PROMOTER

\begin{tabular}{|c|c|c|c|}
\hline $\begin{array}{l}\text { Cis-regulatory } \\
\text { elements }\end{array}$ & $\begin{array}{c}\text { Matrix } \\
\text { sequences }\end{array}$ & Function & References \\
\hline E2FANTRNR & TTTCCCGC & $\begin{array}{l}\text { Involved in upregulation of the promoter } \\
\text { at G1/S transition }\end{array}$ & Sozzani et al. (2006) \\
\hline E2F1OSPNA & GCGGGAAA & $\begin{array}{l}\text { Involved in transcriptional activation in actively } \\
\text { dividing cells and tissue }\end{array}$ & Chabouté et al. (2002) \\
\hline OSE1ROOTNODULE & AAAGAT & $\begin{array}{l}\text { One of the consensus sequence motifs of } \\
\text { organ-specific elements }\end{array}$ & Stougaard et al. (1990) \\
\hline OSE2ROOTNODULE & СТCTT & $\begin{array}{l}\text { (OSE) characteristic of the promoters activated in } \\
\text { infected cells of root nodules }\end{array}$ & \\
\hline AACACOREOSGLUB1 & AACAAAC & Involved in endosperm-specific expression & Wu et al. (2000); \\
\hline ACGTOSGLUB1 & GTACGTG & Involved in endosperm-specific expression & Thomas (1993) \\
\hline PROLAMINBOXOSGLUB1 & TGCAAAG & Involved in endosperm-specific expression & \\
\hline GATA & GATA & Involved in light responsiveness & $\begin{array}{l}\text { Arguello-Astorga and } \\
\text { Herrera-Estella (1998) }\end{array}$ \\
\hline GT-1 & GRWAAW & Involved in light responsiveness & Villain et al. (1996); \\
\hline G box & CACGTG & $\begin{array}{l}\text { Involved in light responsiveness } \\
\text { Involved in light responsiveness }\end{array}$ & $\begin{array}{l}\text { Manzara et al. (1991); } \\
\text { Sawant et al. (2001) }\end{array}$ \\
\hline ABREAZMRAB28 & TCCACGTCTC & ABA-responsive element (ABRE B) & Busk and Pagès (1998) \\
\hline GAREAT & TAACAAR & Gibberellin responsive elements & Ogawa et al. (2003); \\
\hline GARE1OSREP1 & TAACAGA & Gibberellin responsive elements & Sutoh and Yamaghuci \\
\hline GARE2OSREP1 & TAACGTA & Gibberellin responsive elements & $(2003)$ \\
\hline AUXRETGA1GMGH & TGACGTAA & Putative auxin-resonsive element & Liu et al. (1994) \\
\hline LTRE & CCGAA & Low temperature responsive elements & Dunn et al.(1998) \\
\hline MYBCONSENSUSAT & YAACKG & Involved in dehydration and ABA-inducible expression & Ma et al. (2009); \\
\hline MTB1AT & WAACCA & Involved in dehydration and ABA-inducible expression & Abe et al. (2003) \\
\hline MYBARRD22 & CTAACCA & Involved in dehydration and ABA-inducible expression & \\
\hline SURECOREATSULTR11 & GAGAA & Core of sulphur-responsive element & $\begin{array}{l}\text { Maruyama-Nakashita } \\
\text { et al. (2005) }\end{array}$ \\
\hline TC-rich repeats & ATTTTCTCAA & Involved in defense and stress responses & Zhao et al. (2012) \\
\hline
\end{tabular}

Note: uep2 - ubiquitin extension protein.

motif is well conserved within the polyubiquitin, including rice RUBQ2, rubi3, soyabean Gmubi3, Gmubi7, sunflower UbB1, maize Zmubil, and potato $\mathrm{Ubi7}$, suggesting that the motif contributes considerably to the strong expression mediated by polyubiquitin promoter (Hernandez-Garcia and Finer, 2014). Interestingly, a G box like motif is also present in uep2 promoter at position -892 (Figure 2).

\section{Evaluation of Promoter Activity in Oil Palm Tissues}

In order to determine the activity of different regions of the promoter, promoter truncation analysis was performed. The PCR products that contain uep 2 truncation promoter regions with size of $2255 \mathrm{bp}$ and $1194 \mathrm{bp}$ were amplified. The size of amplicon was determined basically based on the presence of putative INTRONLOWER motif (TGCAGg) predicted at position -1095, which is 1194 at length from the start codon. Several studies indicated that the presence of intron at the $5^{\prime}$ untranslated region (5'UTR) could significantly impact gene expression. For region with size of 2255 $\mathrm{bp}$, the fragment consists of the $1194 \mathrm{bp}$ region and spans with about $1000 \mathrm{bp}$ sequence immediately upstream of INTRONLOWER motif. The reporter systems were generated by cloning the full length of uep 2 promoter and the truncation fragments into non-binary vector pBI221, replacing the CaMV35S promoter to drive the gus reporter gene coding sequence. The expression vectors were designated as pUEP2A (3336 bp), pUEP2B (2255 bp) and pUEP2C (1194 bp) (Figure 3).

Histochemical staining for GUS activity was conducted to assess the activity of full length uep2 promoter and its $5^{\prime}$ deletion constructs. In the present study, the relative strength and expression pattern of the uep 2 promoter were compared with the constitutive ubil and CaMV35S promoters. The constructs were bombarded into oil palm tissues and tobacco leaves. Each blue spot detected as a results of GUS activity, whether a single or in a group of cells, was considered as one expression unit (Klein et al., 1987). The GUS activity was determined by scoring the 

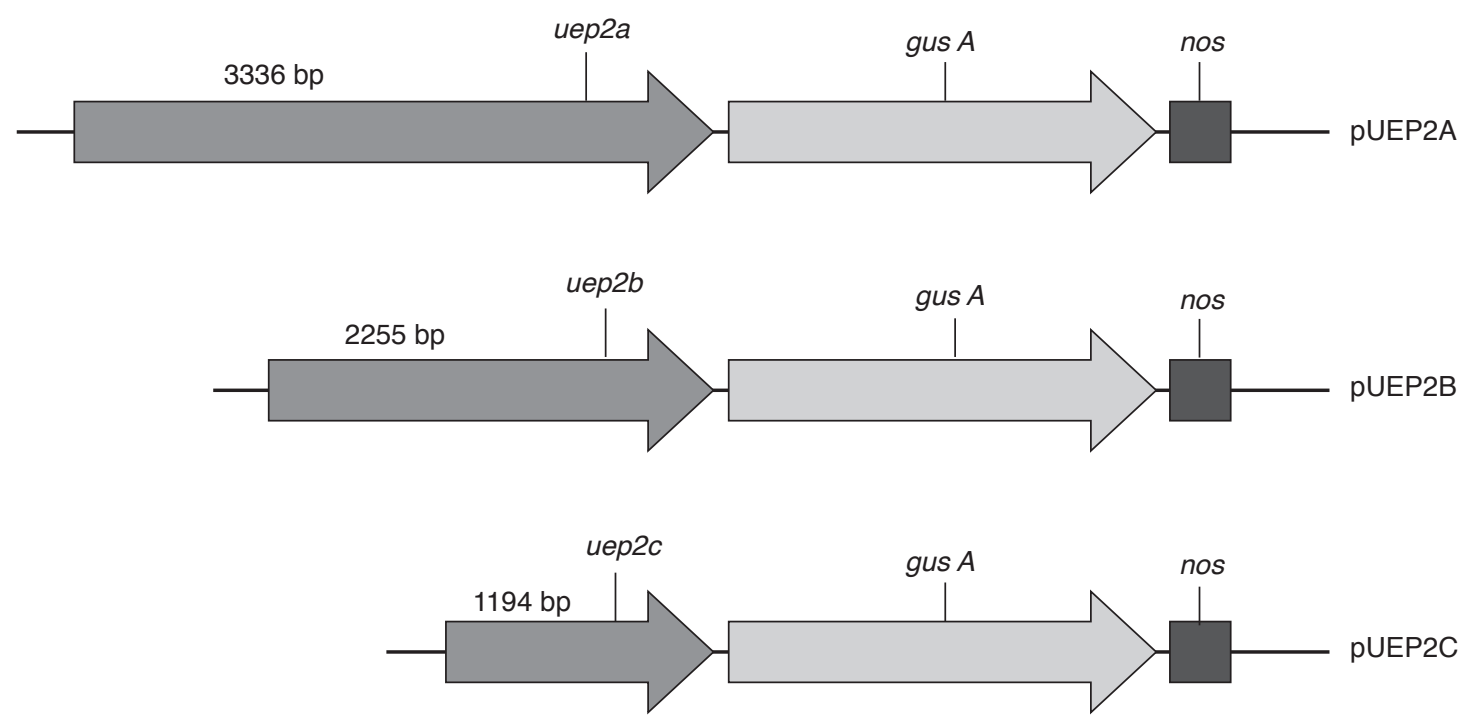

Figure 3. Schematic diagram of the $\beta$-glucuronidase (GUS) constructs containing the ubiquitin extension protein (uep2) promoter. Three uep2 promoter fragments $(3336,2255$ and 1194 with respect to the ATG) were amplified by polymerase chain reaction (PCR) and fused to gus gene in the pBI221 plasmid, replacing CaMV35S.

number of GUS positive spots optically. The data collected were then summarised in the form of mean comparison and standard deviation of five replicates. The GUS histochemical data for each of the constructs are shown in Table 3.

The activity of uep 2 was evaluated in oil palm cabbage or also defined as young leaflet from mature palm (YLMP). The tissue is routinely used as an explant for callus in vitro propagation (Tarmizi et al., 2011). Results indicated that all uep2 constructs were able to direct the expression of GUS in YLMP tissue (Figure 4). The highest activity was shown by uep $2 c$, followed by uер $2 a$ and uep $2 b$. Besides, the GUS histochemical staining was also evaluated in oil palm embryoid (Figure 4). The uep $2 b$ was shown to produce the highest activity, followed by $u е p 2 c$ and uep2a. The results obtained for uep2c was unexpected. GUS should not be expressed in oil palm tissues bombarded with pUEP2C construct since uep2C was predicted as a splice intron region due to the presence of INTRONLOWER motif based on promoter in silico analysis performed using PLACE. Nevertheless, the result could indicate that the prediction might not be accurate as the PLACE database was developed based on cis-regulatory elements found in other vascular plants such as rice and Arabidopsis (Higo et al., 1999).

The activity of uep2 constructs was also evaluated in oil palm plantlets. The constructs were bombarded into the green leaves, stem and roots of plantlets (Figure 4). All uep2 constructs were able to direct the expression of GUS in green leaves and stem. In green leaves, the activity of uep $2 a$ was higher than $u e p 2 b$ and $u e p 2 c$, but the activity was lower compared to $35 \mathrm{~S}$. In stem, uep $2 a$ and $u e p 2 b$ showed a higher expression of GUS than 355 and the activity of uep2c was comparable to 35S. In plantlet roots, the expression of GUS driven by all promoters was very low. The low expression of GUS in root could be due to the inappropriate

TABLE 3. COMPARISON OF PROMOTER STRENGTH BY TRANSIENT gus GENE EXPRESSION AND GUS ACTIVITY IN OIL PALM TISSUES TWO DAYS AFTER BOMBARDMENT

\begin{tabular}{lcccccc}
\hline \multirow{2}{*}{ Promoter/construct } & \multicolumn{5}{c}{ Means (standard error) of GUS foci } \\
\cline { 2 - 7 } & EM & GL & PL ST & T & YMLP & R \\
\hline Ubi1/pAHC25 & $998 \pm 101.73$ & $91.67 \pm 11.67$ & $120.67 \pm 12.33$ & $8 \pm 1.73$ & $1783 \pm 58.77$ & $7 \pm 0.7$ \\
CaMV35S/pBI221 & $665.33 \pm 22.92$ & $50.67 \pm 4.055$ & $60.11 \pm 11.45$ & $81 \pm 20.74$ & $933 \pm 116.75$ & $11 \pm 2.5$ \\
uep2a/pUEP2A & $293.33 \pm 2.73$ & $28.67 \pm 2.60$ & $107.33 \pm 12.33$ & $11 \pm 2.08$ & $331 \pm 63.43$ & $5 \pm 1.2$ \\
uep2b/pUE2B & $534.00 \pm 5.73$ & $30.33 \pm 4.63$ & $85.00 \pm 2.89$ & $30.67 \pm 6.98$ & $370.67 \pm 3.93$ & $5 \pm 0.5$ \\
uep2c/pUEP2C & $522.99 \pm 60.61$ & $5.33 \pm 0.88$ & $50.33 \pm 1.07$ & $9.33 \pm 1.76$ & $460 \pm 37.00$ & 0 \\
\hline
\end{tabular}

Note: *EM - embryoid. GL - green leaves. PL S - plantlet stem. T - tobacco leaves.

YLMP - young leaflet from mature palm. $\quad \mathrm{R}$ - plantlet root. gus - $\beta$-glucuronidase. 

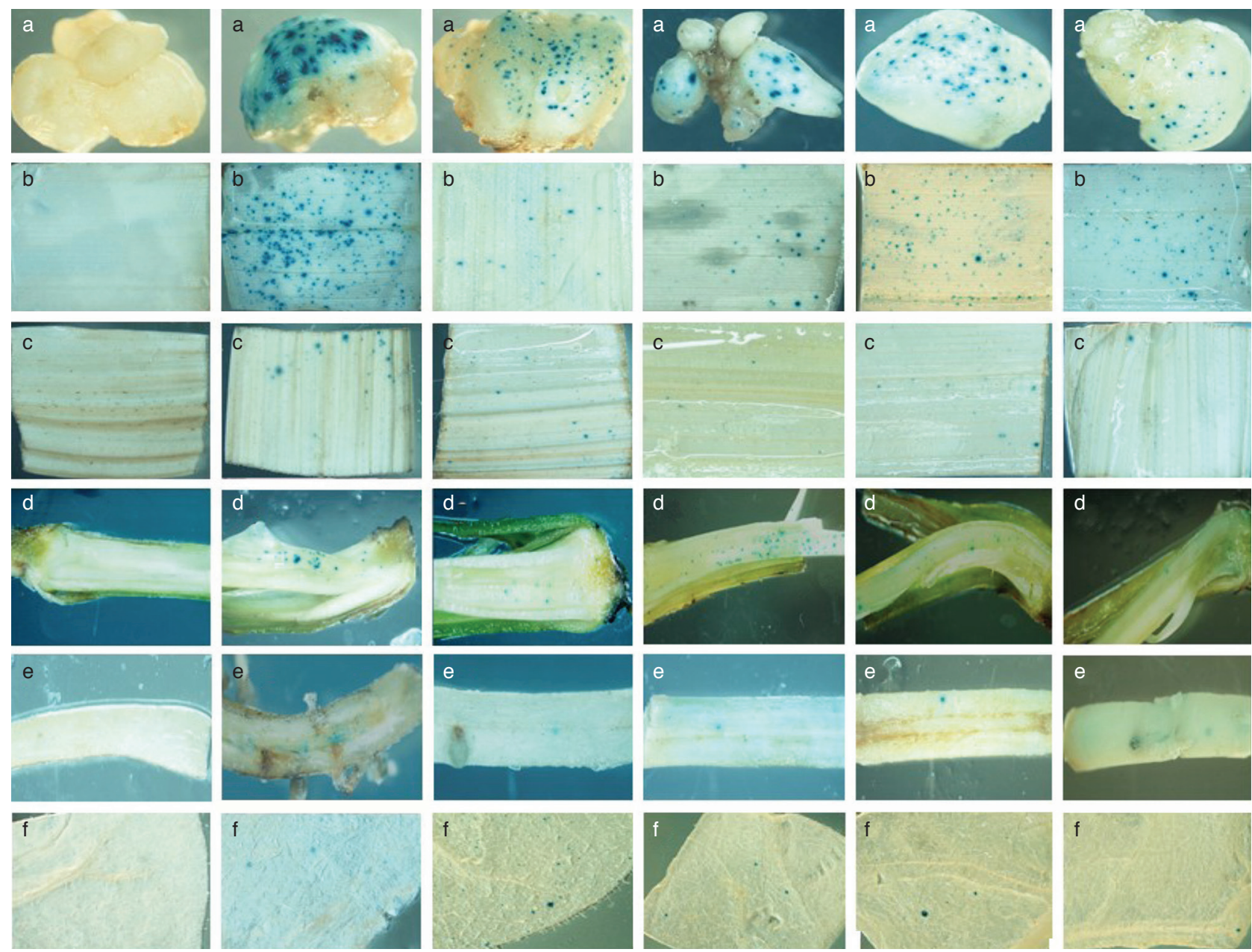

Figure 4. Transient histochemical $\beta$-glucuronidase (GUS) assay in oil palm tissues and tobacco leaves. The tissues were bombarded with constructs carrying ubi1, CaMV35S, uep2A, uep2B and uep2C. a) Embryoid, b) young matured leaflet palm, c) plantlet green leaf, d) plantlet stem, e) plantlet root, and f) tobacco leaf.

parameters of particle bombardment that were used for delivering the plasmid DNA into the tissue. As optimisation of bombardment physical parameters for root has not yet been carried out, delivery of the plasmids into this tissue was only performed using the parameters optimised by Parveez et al. (1997). The optimised parameters were for oil palm transformation using embryogenic calli. The highest activity was observed in the root tissue bombarded with $35 S$, followed by ubi1, uep $2 a$ and uep $2 b$. The activity of uep $2 a$ was similar to uep $2 b$. However, no expression of GUS was observed for uеp $2 c$.

Although uep2 is active in oil palm, its activity is relatively lower than maize ubi1 in most tissues. Ubi1 is a strong constitutive promoter that has been extensively used to express chimeric genes in monocot transformation studies (Streatfield et al., 2004). The promoter was also shown to drive a strong expression of GUS in oil palm tissues as reported by Chowdhury et al. (1997). The Ubi1 activity was also higher than oil palm uep1 and TCTP promoters (Masura et al., 2011; 2010). The use of strong constitutive promoters such as those derived from polyubiquitin or Act1 that are capable of driving high expression of transgenes is certainly desired. However, the use of very strong promoters have shown to have some drawbacks. The excessive promoter activity might lead to the undesirable phenotypes such as growth retardation or abnormalities (Takeda et al., 2003; Potenza et al., 2004). This could possibly be due to the overexpression of a specific transgene at the wrong time in development, particularly in tissues where it is not normally expressed, or expressed at a very high level (Potenza et al., 2004). Moreover, strong plant promoters can also be easily silenced by methylation (Li et al., 2014). Methylation can occur in the exon/intron region of promoter complexes. Methylation of the exon / intron in the ubil promoter complex, and condensation of the chromatin in regions containing transgenes was reported in barley (Meng et al., 2003).

The activity of uep 2 promoter was also investigated in dicotyledonous plant using tobacco leaves as a target tissue. The use of tobacco plant could indicate the potential of uep 2 promoter for 
genetic engineering work of dicots. In addition, it is a suitable model plant to evaluate the efficiency of uep2 promoter for stable expression as oil palm has a long regeneration cycle. Results indicated that all uep 2 constructs were able to direct the expression of GUS, with the highest activity produced by uep $2 b$, followed by uep2a and uep2c (Figure 4). However, the activity of $35 S$ promoter was higher than $u e p 2 b$. This was expected as the activity of $35 S$ was reported to be more effective in dicots than monocots (Battraw and Hall, 1990; Benfey and Chua, 1990). Nevertheless, the results still indicated the potential application of uep 2 promoter in dicots.

In general, the truncated uep $2 b$ promoter showed the highest expression of GUS in most tissues as compared to other uep 2 derivatives. The $u e p 2 b$ was able to direct the expression of GUS in all tissues tested with the high activity detected in oil palm embryoid, green leaves, and tobacco leaves. The full length of uер2 (uер2a) promoter also has the ability to direct the expression of GUS in all tissues with the high activity detected in the plantlet stem. The strength of uep $2 a$ and $u e p 2 b$ was similar in the plantlet roots. By contrast, the uep $2 c$ promoter deletion derivative was shown not effective in driving GUS expression in all tissues tested. Although uep $2 c$ showed a high activity in YLMP and embryoid, a significant drop in GUS expression occurred in green leaves, plantlet stem and tobacco leaves, whereas no expression was observed in plantlet root. These results indicated that the $5^{\prime}$ flanking region of uep2 gene was active in oil palm and tobacco leaves. Deletion of the $2141 \mathrm{bp}$ region between position -1096 and -3237 produced a significant decrease in GUS expression, denoting the presence of important cis-acting regulatory elements or enhancer that are related to the constitutive transcriptional regulation of uеp2 gene.

Regulation of gene expression at the promoter level is mainly controlled by the cis-acting elements localised upstream of the transcriptional initiation sites (Hernandez-Garcia and Finer, 2014). Its mechanism involves complex processes of DNA-protein and protein-protein interactions that are diverse in response to environmental conditions and developmental cues (Manzara et al., 1991). The results so far indicated that the uep2 promoter activities were influenced by the deletion sections of the $5^{\prime}$ upstream sequence. The different sizes of promoter deletions contain the different copy number of cis-elements and have different distribution pattern in promoter region, which may affect the gene expression. For example, GATA box was highly distributed in иер $2 a$ (19 repeats) and $u e p 2 b$ (eight repeats) as compared to uep2c (five repeats) (Figure 2). The GATA elements have been found in many promoters of light-responsive genes such as the RBCS, CAB and GAP (Argüello-Astorga and Herrera-Estella 1998; Jeong and Shih, 2003) and are essential for their high expression levels (Gidoni et al.,1989). Deletion or mutation of GATA elements in both green tissue specific (Lhcb2) and constitutive (CsVMV) promoters have strongly reduced the promoters activity in photosynthetic tissues (Kehoe et al., 1994; Verdaguer et al., 1998). Results indicated that the deletion did not interfere the constitutive expression of gus gene under uep $2 b$. For uеp $2 c$, even though the promoter was active in YLMP and embryoid, its activity decreased particularly in green tissues. This indicated that uep $2 c$ promoter fragment may contain all of necessary regulatory elements but needed strong enhancers to be functional. In $u e p 2 b$ region, the detailed analysis reveals the presence of a 23BPZM27KDAZEIN motif (aatgttggtttcctttagACGCC) at position -1221. The motif confers a high level of transcriptional activity in an orientation-dependent manner (Ueda et al., 1994). The region also has a TA-rich region at -2096 that functions as an enhancer for transcription (Sarmast, 2017). The results showed that the cisregulatory elements that may be necessary for high transcriptional activity were distributed at location -1096 and -3237 . The elements are fully present in uеp $2 a$ and uep $2 b$.

In general, as uep1 (Masura et al., 2010), uep2 promoter strength was also relatively moderate compared to the strong ubil and $35 \mathrm{~S}$ promoters. However, constitutive promoters with a moderate activity level might sometimes be more desirable for genetic engineering application to reduce energy loss and to avoid phenotypic changes ( $\mathrm{Li}$ et al., 2014). It is also useful for the expression of transgenes that are toxic or otherwise inhibitory in abundance, for which a very strong promoter would not be suitable (Park et al., 2010). Toa et al. (2015) reported that the strength of ubiquitin extension protein (JcUEP) promoter from Jatropha was lower than the CaMV35S in most tissues. Nevertheless, the promoter was constitutively active in the transgenic Jatropha and Arabidopsis, and its activity was also maintained under stress condition such as in low temperature, high salts, dehydration and exogenous ABA treatments (Toa et al., 2015). Our results also showed that oil palm uep 2 has the ability to drive the expression of gus reporter gene constitutively and in certain tissues, such as plantlet and embryoid, the uep2 activity was comparable to the $35 S$ promoter.

\section{CONCLUSION}

We have successfully isolated a promoter from ubiquitin extension protein gene (uep2). The activity of uep 2 promoter and its $5^{\prime}$ deletion derivatives was characterised using transient in vitro analysis. Although transient system may not provide definitive information on gene expression 
pattern, the system has served as an indicator that showed the potential of uep 2 as an ideal alternative constitutive promoter for genetic engineering work. Our novel oil palm promoter may also be useful for transgene expression in other monocots and dicots as well as other important crops for beneficial traits.

\section{ACKNOWLEDGEMENT}

We would like to thank the Director-General of MPOB for permission to publish this article. We also would like to acknowledge members of the Advanced Biotechnology and Breeding Centre, MPOB for helpful discussion and technical support. Special thanks to Dr Abdul Masani Mat Yunus for critically reviewing this article. Thanks are extended to the staff of Technology Transgenic Group, MPOB for their kind assistance.

\section{REFERENCES}

Abe, H; Urao,T; Ito, T; seki, M; Shinozaki, K and Yamaguchi-Shinozaki, K (2003). Arabidopsis AtMYC2 (bHLH) and AtMYB2 (MYB) function as transcriptional activators in abscisic acid signalling. Plant Cell, 15(1): 63-78.

Argüello-Astorga, G and Herrera-Estrella, L (1998). Evolution of light regulated plant promoters. Annu. Rev. Plant Biol., 49(1): 525-555.

Bacha, S; Khatoon, A; Asif, M; Yuan, J and Bashir, A (2015). Deletion analysis of susy-SI promoter for the identification of optimal promoter sequence. Pak. J. Bot., 47(4): 1287-1292.

Battraw, M J and Hall, T C (1990). Histochemical analysis of CaMV35S promoter- $\beta$-glucuronidase gene expression in transgenic rice plants. Plant Mol. Biol., 15: 527-538.

Benfey, P N and Chua, N-H (1990). The cauliflower mosaic virus $35 \mathrm{~S}$ promoter: Combinatorial regulation of transcription in plants. Science, 250: 959-966.

Benfey, P N; Ren, L and Chua, N H (1990). Tissuespecific expression from CaMV35S enhancer subdomains in early stages of plant development. The EMBO J., 9: 1677-1684.

Callis, J; Raasch, J A and Vierstra, R D (1990). Ubiquitin extension proteins of Arabidopsis thaliana. J. Biol. Chem., 265: 12486-12493.
Chabouté, M E; Clément, B and Philipps, G (2002). $S$ phase and meristem-specific expression of the tobacco RNR1b gene is mediated by an E2F element located in the 5' leader sequence. J. Biol. Chem., 17: 277(20), 17845-17851.

Chang, W-C; Lee, T-Y; Huang, H-D; Huang, H-Y and Pan, R-L (2008). PlantPAN: Plant promoter analysis navigator, for identifying combinatorial cis-regulatory elements with distance constraint in plant gene groups. BMC Genomics, 9: 561.

Chen, Q-J; Xie, M; Ma, X-X; Dong, L; Chen, J and Wang, X-C (2010). MISSA is a highly efficient in vivo DNA assembly method for plant multiplegene transformation. Plant Physiol., 153(1): 41-51. DOI:10.1104/pp.109.152249.

Chowdhury, M K U; Parveez, G K A and Norihan, M S (1997). Evaluation of five promoters for use in transformation of oil palm (Elaeis guineensis Jacq.). Plant Cell Rep., 16: 277-281.

Christensen, A H; Sharrock, R A and Quail, P H (1992). Maize polyubiquitin genes: Structure, thermal perturbation of expression and transcript splicing, and promoter activity following transfer of protoplast by electroporation. Plant Mol. Biol., 18: 675-689.

Cornejo, M J; Luth, D; Blankenship, K M; Anderson, O D and Blechl, A E (1993). Activity of maize ubiquitin promoter in transgenic rice. Plant Mol. Biol., 23: 567-581.

Doyle, J J and Doyle, J L (1990). Isolation of plant DNA from fresh tissue. Focus, 12 (1): 13-15.

Douglas Des Moines, R (2004). Maize alpha-tubulin 3-18 promoter. European patent No. EP 1464707 B1. European Patent Office.

Dunn, M A; White, A J; Vural, S and Hughes, M A (1998). Identification of promoter elements in a lowtemperature-responsive gene (blt4.9) from barley (Hordeum vulgare L.). Plant Molecular Biology, 38: 551564.

Elmayan, T and Vaucheret, H (1996). Expression of single copies of a strongly expressed 35S transgene can be silenced post-transcriptionally. Plant J., 9: 787-797.

Eeuwans, C J (1976). Mineral requirement for growth and callus initiation of tissue explants from mature coconut palms (Cocos nucifera) cultured in vitro. Physiol. Plant, 36: 23-38.

Fang, R X; Nagy, F; Sivasubramaniam, S and Chua, N-H (1989). Multiple cis regulatory elements for 
maximal expression of the cauliflower mosaic virus $35 S$ promoter in transgenic plants. Plant Cell, 1: 141150.

Finley, D; Bartel, B and Varshavsky, A (1989). The tails of ubiquitin precursors are ribosomal proteins whose fusion to ubiquitin facilitates ribosome biogenesis. Nature, 338: 394-401.

Garbarino, J E and Belknap, W R (1994). Isolation of an ubiquitin-ribosomal protein gene (ubi3) from potato and expression of its promoter in transgenic plants. Plant Mol. Biol., 24: 119-127.

Gausing, K and Jensen, C B (1986). Ubiquitin longtail fusion genes arranged as closely spaced direct repeats in barley. Gene, 94: 165-171.

Gidoni, D; Brosio, P; Bond-Nutter, D; Bedbrook, J and Dunsmuir, P (1989). Novel cis-acting elements in Petunia Cab gene promoters. Mol. Gen. Genet., 215(2): 337-44.

Hanin, A N; Masani, A M Y and Parveez, G K A (2016). Evaluation of oil palm leaf-specific promoter (LSP1) activity for expressing phb genes in Arabidopsis thaliana. J. Oil Palm Res. Vol. 28(1): 1-9.

Hernandez-Garcia, C M and Finer, J J (2014). Identification and validation of promoters and cisacting regulatory elements. Plant Sci., 217-218: 109119.

Higo, K; Ugawa, $\mathrm{Y}$; Iwamoto, $\mathrm{M}$ and Korenaga, T (1999). Plant cis-acting regulatory DNA elements (PLACE) database. Nucleic Acids Res., 27 (1): 297-300.

Ho, M-W; Ryan, A and Cummins, J (1999). Cauliflower mosaic virus promoter - A recipe for disaster?. Microb. Ecol. Health Dis., 11: 194-197.

Hoffman, N E; Kenton, K; Milkowski, D and Pichersky, E (1991). Isolation and characterization of tomato cDNA and genomic clones encoding the ubiquitin gene ubi3. Plant Mol. Biol., 17: 11891201.

Holme, I B; Wendt, T and Holm, P B (2013). Intragenesis and cisgenesis as alternatives to transgenic crop development. Plant Biotechnol J., 11(4): 395-407.

Jeong, M-J and Shih, M-C (2003). Interaction of a GATA factor with cis acting elements involved in light regulation of nuclear genes encoding chloroplast glyceraldehyde-3-phosphate dehydrogenase in Arabidopsis. Biochem Biophys Res. Commun., 300(2): 555-562.
Kehoe, D M; Degenhardt, J; Winicov, I and Tobin, E M (1994). Two 10-bp regions are critical for phytochrome regulation of a Lemna gibba Lhcb gene promoter. Plant Cell Online, 6(8): 1123-1134.

Klein, T M; Wolf, E D; Wu, R and Sanford, J C (1987). High velocity microprojectiles for delivering nucleic acids into living cells. Nature, 327: 70-73.

Kloti, A; He, X; Potrykus, I; Hohn, T and Futterer, $\mathrm{J}$ (2002). Tissue-specific silencing of a transgene in rice. Proc. Natl Acad. Sci. USA, 99: 10881-10886.

Last, D L; Brettell, R I S; Chamberlain, D A; Chowdhury, A M; Larkin, P J; Marsh, E L; Peacock, W J and Dennis, E S (1991). pEmu: An improved promoter for gene expression in cereal. Theor. Appl. Genet., 81: 581-588.

Lescort, M; Dehais, P; Thijs, G; Marchal, K; Moreau, Y; Van De Peer, Y; Rouze, P and Rombauts, S (2002). PlantCARE, a database of plant cis-acting regulatory elements and portal tolos for in silico analysis of promoter sequences. Nucleic Acids Res., 30: 325-327.

Li, J; Xu R-F; Qin, R-Y; Ma, H; Li, H; Zhang, Y-P; Li, L; Wei, P-C and Yang, J-B (2014). Isolation and functional characterization of a novel rice constitutive promoter. Plant Cell Rep., 33(10): 16511660.

Liu, Z B; Ulmasov, T; Shi, X; Hagen, G and Guilfoyle, T J (1994). Soybean GH3 promoter contains multiple auxin-inducible elements. Plant Cell, 5: 645-57.

Manzara, T; Carrasco, P and Gruissem, W (1991). Developmental and organ-specific changes in promoter DNA-protein interactions in the tomato rbcS gene family. Plant Cell, 3: 1305-1316.

Ma, Q; Dai, X; Xu, Y; Guo, J; Liu, Y; Chen, N and Chong, K (2009). Enhanced tolerance to chilling stress in OsMYB3R-2 transgenic rice is mediated by alteration in cell cycle and ectopic expression of stress genes. Plant Physiol., 150(1): 244-256.

Maruyama-Nakashita, A; Nakamura, Y; WatanabeTakahashi, A; Inoue, E; Yamaya, T and Takahashi, H (2005). Identification of a novel cis-acting element conferring sulfur deficiency response in Arabidopsis roots. Plant J., 42(3): 305-314.

Masani, M Y A; Izawati, A M D; Rasid, O A and Parveez, G K A (2018). Biotechnology of oil palm: Current status of oil palm genetic transformation. Biocatal. Agric. Biotechnol., 15: 335-347.

Masura, S S; Parveez, G K A and Eng Ti, L L (2011). Isolation and characterization of oil palm 
constitutive promoter derived from translationally control tumor protein (TCTP) gene. Plant Physiol. Biochem., 49: 701-708.

Masura, S S; Parveez, G K A and Ismanizan, I (2010). Isolation and characterization of oil palm constitutive promoter derived from ubiquitin extension protein (uep1) gene. New Biotechnol., 27: 289-299.

Masura, S S; Tahir, N I; Rasid, O A; Ramli, U S; Othman, A; Masani, M Y A; Parveez, G K A and Kushairi, A (2017). Post-genomic technologies for the advancement of oil palm research. J. Oil Palm Res. Vol. 29(4): 469-486.

McElroy, D; Zhang, W; Cao, J and Wu, R (1990). Isolation of an efficient actin promoter for use in rice transformation. Plant Cell, 2: 163-171.

Meng, L; Bregitzer, P; Zhang, S and Lemaux, P G (2003). Methylation of the exon/intron region in the Ubi1 promoter complex correlates with transgene silencing in barley. Plant Mol. Biol., 53(3): 327-340.

Monia, B P; Ecker, D J and Crooke, S T (1990). New perspectives on the structure and function of ubiquitin. Bio/technol., 8: 209-215.

Mubeen, H; Shoaib, M W; Shoaib, S; Jabeen, S and Raza, S (2015). In silico analysis of constitutive dicot tubulin gene promoter. IOSR J. Pharmacy and Biological Sciences (IOSR-JPBS), 10: 6-19.

Murashige, T and Skoog, F (1962). A revised medium for rapid growth and bioassays with tobacco tissue cultures. Physiol. Plant., 15: 473-497.

Odell, J T; Nagy, F and Chua, N-H (1985). Identification of DNA sequences required or activity of the cauliflower mosaic virus $35 S$ promoter. Nature, 313: $810-812$

Ogawa, M; Hanada, A; Yamauchi, Y; Kuwahara, A; Kamiya, Y and Yamaguchi, S (2003). Gibberellin biosynthesis and response during Arabidopsis seed germination. Plant Cell, 15(7): 1591-604.

Ozkaynak, E; Finley, D; Solomon, M J and Varshavsky, A (1987). The yeast ubiquitin genes: A family of natural gene fusions. EMBO J., 6: 1429-1439.

Park, S-H; Yi, N; Kim, Y S; Jeong, M-H; Bang, S-W; Choi, Y-D and Kim, J-K (2010). Analysis of five novel putative constitutive gene promoters in transgenic rice plants. J. Exp. Bot., 61(9): 2459-2467.

Parveez, G K A; Rasid, O; Zainal, A; Masri, M M; Majid, N A; Fadillah, H H; Yunus, A M M and Cheah, S C (2000). Transgenic oil palm: Production and projection. Biochem. Soc. Trans., 28 (6): 969-972.
Parveez, G K A; Chowdhury, M K U and Saleh, N M (1997). Physical parameters affecting transient GUS gene expression in oil palm (Elaeis guineensis Jacq.) using the biolistic device. Ind. Crops Prod., 6: 41-50.

Parveez, G K A; Rasid, O A; Masani, M Y A and Sambanthamurhi, R (2015). Biotechnology of oil palm: strategies towards manipulation of lipid content and composition. Plant Cell Rep., 34: 533-543.

Potenza, C; Aleman, L and Sengupta-Gopalan, C (2004). Targeting transgene expression in research, agriculture, and environmental applications: Promoters used in plant transformation. In vitro Cell. Dev. Biol., 40: 1-22.

Rasid,OA;Parveez, GKA;Ho, CL;Sambanthamurhi, R and Napis, S (2009). Plant carotenoids: Molecular genetics and regulation. J. Oil Palm Res. Vol. 21(6): 588-601.

Ravigadevi, S; Rajinder, S; Parveez, G K A; Meilina, O A and Kushairi, D (2009). Opportunities for oil palm via breeding and biotechnology. Breeding Plantation Tree Crop (Jain, S M and Priyadarshan, P M eds.). Springer, New York. p. 377-422.

Sambrook, J; Fritsch, E F and Maniatis, T (1989). Molecular Cloning: A Laboratory Manual (Second edition). Cold Spring Harbor Laboratory Press, USA.

Sawant, S; Singh, P K; Madalana, R and Tuli, R (2001). Designing of an artificial expression cassette for the high level expression of transgenes in plants. Theor. Appl. Genet., 102: 653-644.

Sibe'ril, Y; Doireau, P and Gantet, P (2001). Plant bZIP G-box binding actors. Eur. J. Biochem., 268: 5655-5666.

Sarmast, M K (2017). In silico functional analysis of FLC and FT-genes responsible for postponing and accelerating the onset flowering. J. Proteomics and Bioinformatics, 10: 11.

Sozzani, R; Maggio, C; Varotta, S; Canova, S; Bergounioux, C; Albani, D and Cella, R (2006). Interplay between Arabidopsis activating factors E2Fb and $\mathrm{E} 2 \mathrm{Fa}$ in cell cycle progression development. Plant Physiol., 140: 1355-1366.

Streatfield, S J; Magallanes-Lundback, M E; Beifuss, K K; Brooks, C A; Harkey, R L; Love, R T; Bray, J; Howard, J A; Jilka, J M and Hood, E E (2004). Analysis of the maize polyubiquitin-1 promoter heat shock elements and generation of promoter variants with modified expression characteristics. Transgenic Res., 13: 299-312. 
Sutoh, K and Yamauchi, D (2003). Two cis-acting elements necessary and sufficient for gibberellinupregulated proteinase expression in rice seeds. Plant J., 5: 635-645.

Stougaard, J; Jørgensen, J E; Christensen, T; Kühle, A and Marcker, K A (1990). Interdependence and nodule specificity of cis-acting regulatory elements in the soybean leghemoglobin $l b c 3$ and N23 gene promoters. Mol. Gen. Genet., 220(3): 53-60.

Takeda, T; Suwa, Y; Suzuki, M; Kitano, H; UeguchiTanaka, M; Ashikari, M; Matsuoka, M and Ueguchi, C (2003). The OsTB1 gene negatively regulates lateral branching in rice. Plant J., 33(3): 513-520.

Tarmizi, A H; Zamzuri, I; Ooi, S-E; Samsul Kamal, R; Chan, P L; Rohani, O and Ong-Abdullah, M (2011). Forging a head with clones. Further Advances in Oil Palm Research (2000-2010) (Mohd Basri, W; Choo, Y $\mathrm{M}$ and Chan, K W eds.). MPOB, Bangi. p. 102-140.

Thomas, T L (1993). Gene expression during embryogenesis and germination: An overview. Plant Cell, 5: 1401-1410.

Toa, Y-B; He, L-L; Niu, L-J and Xu, Z-F (2015). Isolation and characterization of an ubiquitin extension protein gene (JcUEP) from Jatropha curcas. Planta, 241: 823-836.

Ueda, T; Wang, Z; Pham, N and Messing, J (1994). Identification of a transcriptional activator-binding element in the 27-kilodalton zein promoter, the -300 element. Mol. Cell Biol., 14(7): 4350-4359.

Verdaguer, B; De Kochko, A; Fux, C I; Beachy, R N and Fauquet, C (1998). Functional organization of the cassava vein mosaic virus (CsVMV) promoter. Plant Mol. Biol., 37(6): 1055-1067.

Villain, P; Mache, R and Zhou, D X (1996). The mechanism of GT element-mediated cell type- specific transcriptional control. J. Biol. Chem., 20: 32593-32598.

Wang, J and Oard, J H (2003). Rice ubiquitin promoters: Deletion analysis and potential usefulness in plant transformation systems. Plant Cell Rep., 22: 129-134.

Wu, C-Y; Washida, H; Onodera, Y and Takaiwa, F (2000). Quantitative nature of prolamin box, ACAA and ACGT motifs in a rice glutelin gene promoter: Minimal cis element requirements for endosperm-specific gene expression. The Plant J., 23(3): 415-421.

Wu, K; Malik, K; Tian, L; Hu, M; Froster, E; Brown, D and Miki, B (2001). Enhancers and core promoter elements are essential for the activity of a cryptic gene activation sequence from tobacco, tCUP. Mol. Genet. Genomics, 265: 763-770.

Xiao, K; Zhang, C; Harrison, $M$ and Wang, Z-Y (2005). Isolation and characterization of a novel plant promoter that directs strong constitutive expression of transgenes in plants. Mol. Breed., 15: 221-231.

Zhao, J-P; Jiang, X-L; Zhang, B-Y and Su, X-H (2012). Involvement of microRNA-mediated gene regulation in the pathological development of stem cancer disease in Populus trichocarpa. PLoS One, 7(9): 1-10.

Zeng, Y and Yang, T (2002). RNA isolation from highly viscous samples rich in polyphenols and polysaccharides. Plant. Mol. Biol. Rep., 20: 417a-417e.

Zubaidah, R; Nurniwalis, A W; Chan, P L; Siti Masura, S; Siti Nor Akmar, A and Parveez, G K A (2018). Tissue-specific promoters: The importance and potential application for genetic engineering in oil palm. J. Oil Palm Res. Vol. 30(1): 1-12. 